\title{
Significantly Improved Mechanical Properties of 1100 Aluminium Alloy via Particle Reinforcement
}

\author{
A.O Adetunla ${ }^{1}$, E.T Akinlabi $^{2}$ \\ ${ }^{1}$ Department of Mechanical Engineering Science, University of Johannesburg, Johannesburg \\ 2006, South Africa. \\ ${ }^{2}$ Department of Mechanical Engineering Science, University of Johannesburg, Johannesburg \\ 2006, South Africa.
}

\begin{tabular}{l} 
ARTICLE INFO \\
\hline Keywords: \\
fly ash; multi pass FSP; \\
PKSA; surface metal \\
matrix composites; Ti- \\
62222; 304 Stainless \\
Steel
\end{tabular}

\section{Introduction}

Due to good corrosion resistance and high strength of aluminum alloys, they are majorly used in industries such as automobile, marine and aerospace. Aluminum(Al) and its alloys have excellent formability and are easily weldable, it is well established that aluminum and its alloys exhibit high ductility, strength to weight ratio, electrical and thermal conductivity(Asif, Chandra, and Misra 2011).Consequently, wide range of industries utilizes aluminum and its alloys as the major materials for construction. Although, $\mathrm{Al}$ and its alloys have good strength and also exhibit a high strength to weight ratio, however, they have low corrosion resistance (Sivakumar et al. 2014). Research has shown that $\mathrm{Al}$ and its alloys can have better mechanical properties and high hardness by reinforcing them with ceramic particles. However, these fabricated composites undergo loss in toughness and ductility as a result of the combination of non-deformable ceramic particles (R. S. Mishra, Ma, and Charit 2003). For various applications, it is appropriate that only 
the surface layer of metals is reinforced by ceramic particles to improve the mechanical properties while the majority of the metals maintain the original structure with a greater toughness(Adetunla and Akinlabi 2018; Ikumapayi, Akinlabi, and Majumdar 2018). A lot of methods have been established and used to prepare Al matrix aggregates such as stir casting, squeeze casting, and friction stir processing. Friction Stir Processing (FSP) purposes great advantages in fabricating surface composites when compared to other methods (Rana, Badheka, and Kumar 2016).

Friction Stir Processing (FSP), which has same working principle as Friction Stir Welding(FSW) is one of the methods used to create MMCs. Limitations such as porosity, microstructural defects and particle agglomeration can be solved with FSP(Khodabakhshi et al. 2015). During FSP, plastic deformation of metal is caused by the rotating tool inserted the work piece, heat is generated by the tool shoulder which is in contact with the surface of the metal thus deforming the work piece. Reinforcements such as SiC(Luo et al. 2018), Al2O3(Ahmadkhaniha et al. 2016), SiO2(Khayyamin, Mostafapour, and Keshmiri 2013) have been added into Aluminum alloy to improve its mechanical properties and resistance to corrosion by some studies.

In this study, multi pass FSP is employed on $1100 \mathrm{Al}$ alloy to study the effect of reinforcements on its hardness, tensile strength and corrosion performance. The reinforcements used are Palm Kernel Shell ash, 304 Stainless steel, fly ash and Ti-62222 powder. The aim of this study is to attain improved mechanical properties of $1100 \mathrm{Al}$ by comparing the effect of various reinforcements on it, reinforcement particles offering the highest hardness, finest grain size, highest tensile strength and good corrosion resistance will be investigated. The reinforcement used in this study has been investigated by some studies to reveal their peculiar characterization(Abegunde, Akinlabi, and Madyira 2017; Ikumapayi, Akinlabi, and Majumdar 2018; Panwar and Chauhan 2018). No published literature compared the effect of the various reinforcements used in this study as far as the authors know. The results obtained are discussed extensively.

\section{Experimental Methodology}

$5 \mathrm{~mm}$ sheet thickness of economically accessible $1100 \mathrm{Al}$ alloy were used for the experiment, with its Chemical and mechanical properties presented in Table I. Four different reinforcements are used, namely Fly ash, 304 Stainless steel, Palm Kernel Shell Ash (PKSA) and Ti-62222 powder. Table II shows their chemical compositions and their average particle size of the powder were found to be $59.75 \mu \mathrm{m}$ for PKSA, $69.26 \mu \mathrm{m}$ for Fly ash, $57.14 \mu \mathrm{m}$ for 304 stainless steel and $65.23 \mu \mathrm{m}$ for Ti-62222 powder. $20 \%$ of the strengthening particles were deposited into the different grooves made on the aluminum alloys and subsequently subjected to three cumulative passes. 
Table I: Chemical composition and mechanical properties of $1100 \mathrm{Al}$ alloy

\begin{tabular}{|llllll|lll|}
\hline \multicolumn{4}{|l|}{ Chemical compostion/wt-\% } & & \multicolumn{3}{l|}{ Mechanical properties } \\
\hline $\mathrm{Al}$ & $\mathrm{Cu}$ & $\mathrm{Zn}$ & $\mathrm{Fe}$ & $\mathrm{Si}$ & Others & \multicolumn{2}{l|}{$\begin{array}{l}\text { Tensile Strength } \\
\text { Hardness }\end{array}$} & Elongation \\
\hline 97 & 0.15 & 0.09 & 0.95 & 0.95 & 0.86 & $110 \mathrm{MPa}$ & $12 \%$ & $28 \mathrm{HV}$ \\
\hline
\end{tabular}

Table II: Chemical composition of all reinforcements in wt (\%)

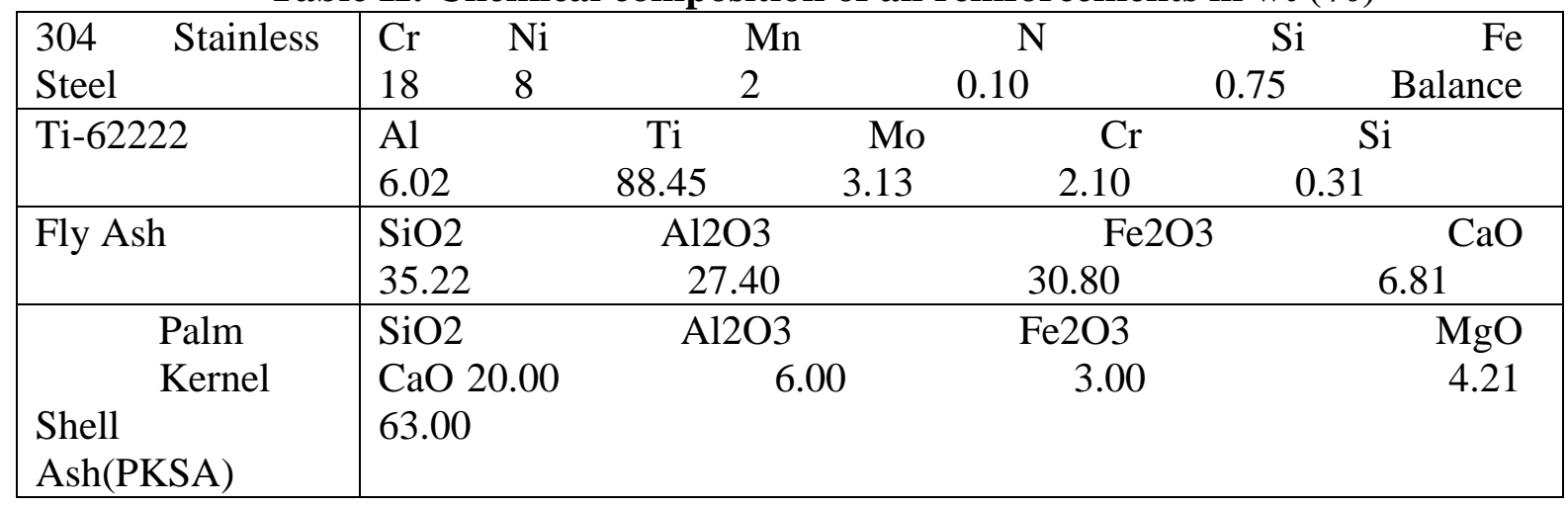

Friction stir processing machine used to fabricate the samples is shown in Figure 1a, it has 12 HP spindle motor with a clockwise as well as anticlockwise spindle rotation, it also has a capacity of up to $3500 \mathrm{rpm}$ turning speed and $50 \mathrm{kN}$ plunge load capability. The FSP tool utilized for the procedure was made of heat-treated H13 steel, with $20 \mathrm{~mm}$ shoulder diameter, pin length and width of equal $4 \mathrm{~mm}$ as seen in Figure $2 \mathrm{~b}$. Figure $2 \mathrm{c}$ represents the appearance of the already processed aluminum sheet. The parameter used for the FSP samples was a plunge speed of $100 \mathrm{~mm} / \mathrm{min}$, a constant tool rotational speed of $1200 \mathrm{rpm}$, and $30 \mathrm{mmm} / \mathrm{mm}$ traverse speed. To ensure even distribution of particles when reinforcing metal matrix composites during FSP, at least three passes must be employed(Adetunla and Akinlabi 2018b), thus, three cumulative passes were used to fabricate the $\mathrm{Al}$ alloy with $100 \%$ overlap. Optical Microscopy $(\mathrm{OM})$ was used to examine the microstructural evolution and the grain sizes of the processed samples. A mircohardness tester were used to conduct the Vickers microhardness with standard in line with ASTM E92-82(Wu et al. 2015), dwell time and load are 15 seconds and 300KN respectively. Instron tensile machine was used for the tensile tests with $2.0 \times 10-3 \mathrm{~s}-1$ strain rate. 
(a)

(b)

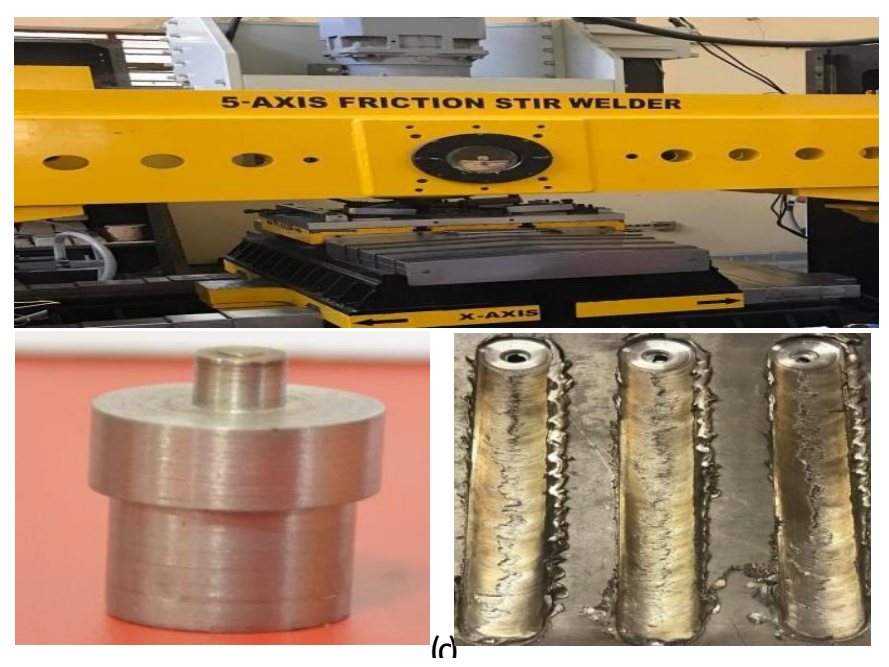

Figure 1: (a) 5 axis Friction stir welding machine developed for FSP, (b)FSP tool used, (c) Crown appearance of the specimen after one pass showing macrostructural defects

\section{Results and Discussion}

\subsection{Microstructural Observations of the composites}

After three cumulative passes, the microstructure of the composites were observed with Optical microscope $(\mathrm{OM})$. No macrostructural defects were observed within the matrix of all composites, the particles were evenly distributed as shown in figure 2 . It can be seen from the microstructure that multi pass friction stir processing helps to break down the reinforcing particles, thus making the particles evenly distributed within the matrix. The stirring action associated with multi pass FSP causes plastic deformation of metals, thus making the stir zone of the metal matrix composites to be characterized with fine grains. 304 Stainless reinforced sample exhibits the finest grain size measured to the average of $5.1 \mu \mathrm{m}$ and the least grain refinement can be seen with the fly ash reinforced samples, owing to the tendency of fly ash to cluster together at the grain boundaries. 


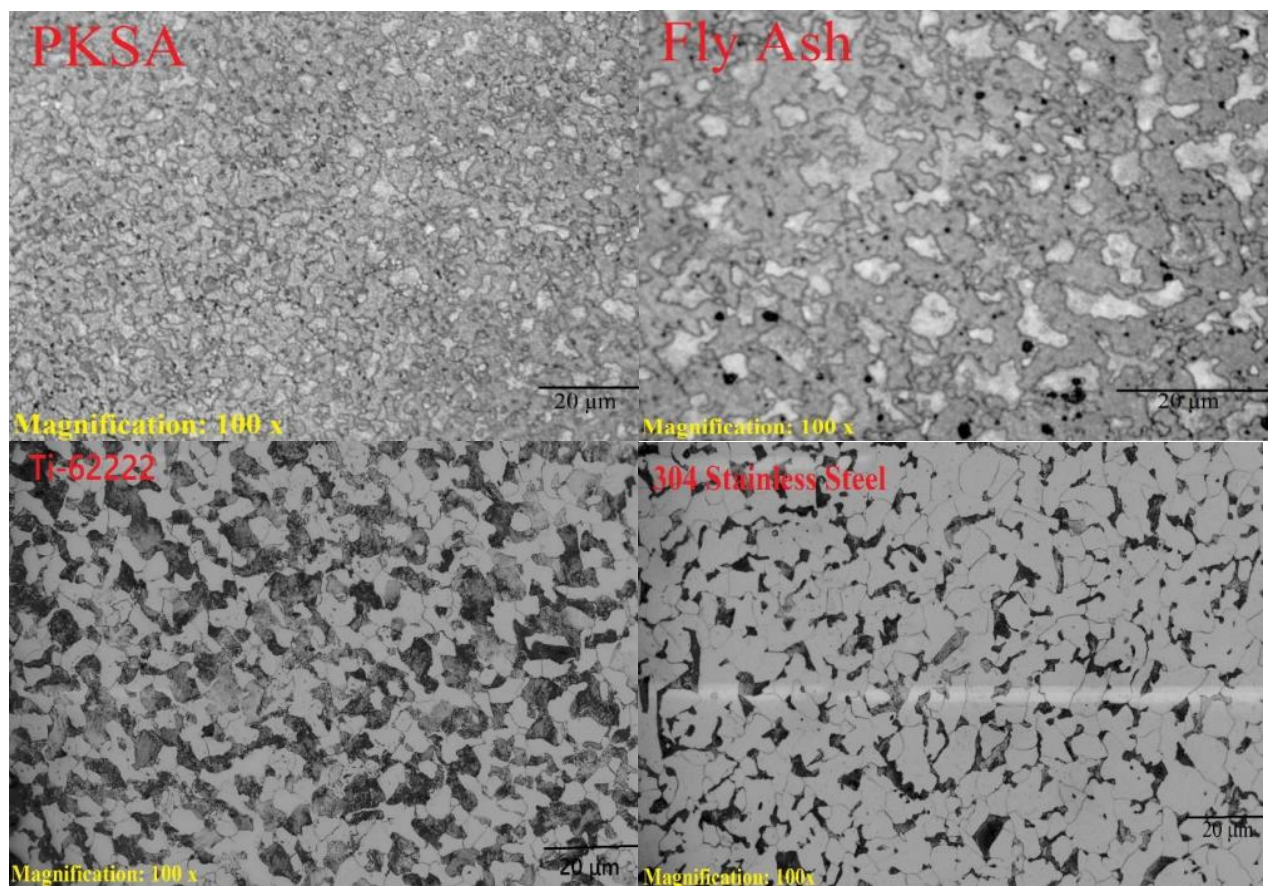

Figure 2: Optical Micrograph of various fabricated composites

\subsection{Hardness and Tensile Properties}

Table III presents the average hardness results of the composites. To ensure an accurate test result, three measurements were conducted for each sample and the average hardness values were reported in this table. The addition of reinforcements improve greatly the hardness performance of $1100 \mathrm{Al}$. Multi pass FSP ensures adequate bonding between the reinforcements and the matrix leading to increase in Vickers hardness(Hashemi and Hussain 2015). 304 Stainless reinforced composite exhibits highest hardness of $95.25 \mathrm{HV}$, which shows $62 \%$ increment in hardness value when compared with the $1100 \mathrm{Al}$. This result may be attributed to the properties of stainless steel, which exhibit higher hardness value. From the microhardness profile in figure 3, it can be seen that the stir zone where the powders were deposited exhibit the highest hardness value.

Table III: Average Hardness Values of Composites

\begin{tabular}{|l|l|}
\hline Composites & Hardness Value (HV) \\
\hline 304 Stainless steel/ Al & 95.23 \\
\hline Fly Ash/ Al & 62.14 \\
\hline Ti-62222/Al & 77.56 \\
\hline PKSA/Al & 75.3 \\
\hline
\end{tabular}




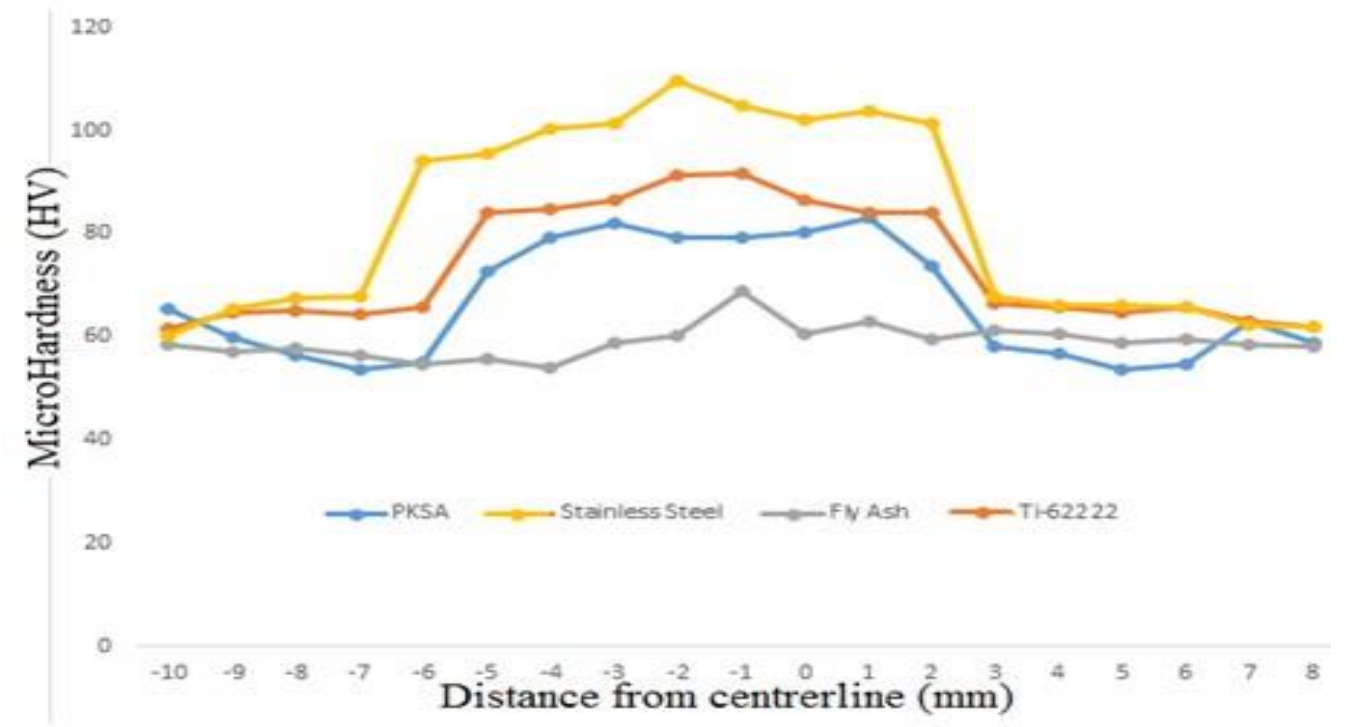

Figure 3: Micro hardness profile of composite samples

The tensile specimen were prepared as seen in Figure 4a and the images of the processed tensile samples are seen in figure $4 \mathrm{~b}$. To ensure accuracy, three test measurement were conducted and the average value for each sample were reported in Table 4. Deformation occurs during FSP in various region which leads to localized strain, thus, fracture occurs at the region with peak localization of strain(Sunil et al. 2016). Alloy type and morphology of the reinforcement used are the major determinant of the location where tensile fracture will occur as revealed by recent studies(Charit and Mishra 2017; Zhang et al. 2018).

(a)

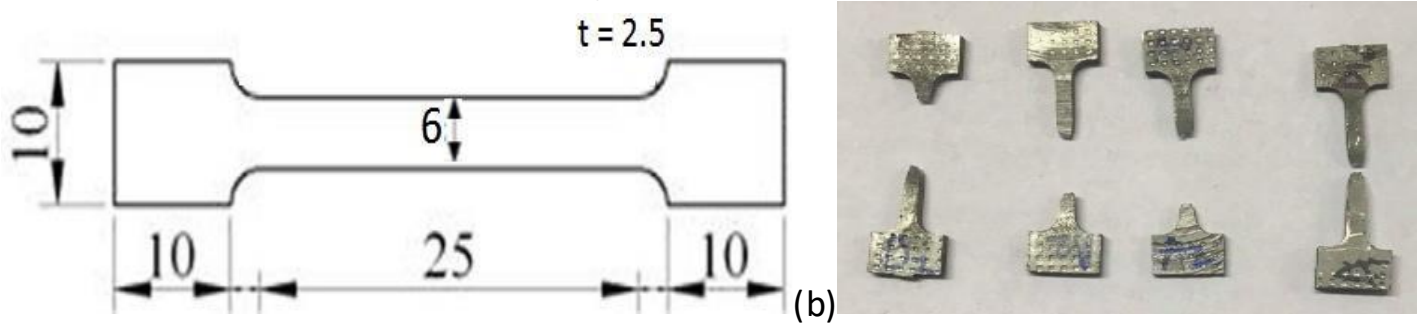

Figure 4: (a) Dimension of specimen for tensile test (b) Fractured samples after Test

Table 4. Tensile properties of the composite samples.

\begin{tabular}{|l|l|l|l|}
\hline Composites & $\begin{array}{l}\text { Yield stress } \\
(\mathbf{M P a})\end{array}$ & $\begin{array}{l}\text { Tensile Strength } \\
(\mathbf{M P a})\end{array}$ & Elongation (\%) \\
\hline FlyAsh/Al & 59.14 & 268.52 & 31.00 \\
\hline PKSA/ Al & 64.36 & 281.71 & 70.34 \\
\hline Ti-62222/ Al & 89.92 & 305.54 & 70.47 \\
\hline $\begin{array}{l}\text { 304 Stainless Steel/ } \\
\text { Al }\end{array}$ & 105.86 & 454.18 & 71.56 \\
\hline
\end{tabular}

From the result obtained in this study, it can be said that 304 Stainless steel reinforced sample exhibits tensile properties when compared with other reinforcements used. However, the composites have almost similar percentage of elongation except for the sample reinforced with 
fly ash. The load-displacement curve shown in Figure 6 reveals that 304 Stainless steel has high tensile strength, which could be seen as a good reinforcing material to Al alloy. However, the fluctuating waves seen with the fly ash reinforced samples can be attributed to the morphology of the fly ash particles; fly ash has tendency to cluster together at grain boundaries, also, reinforcement particles sometimes act as inclusion and impurities within the matrix(M. K. Mishra et al. 2018).

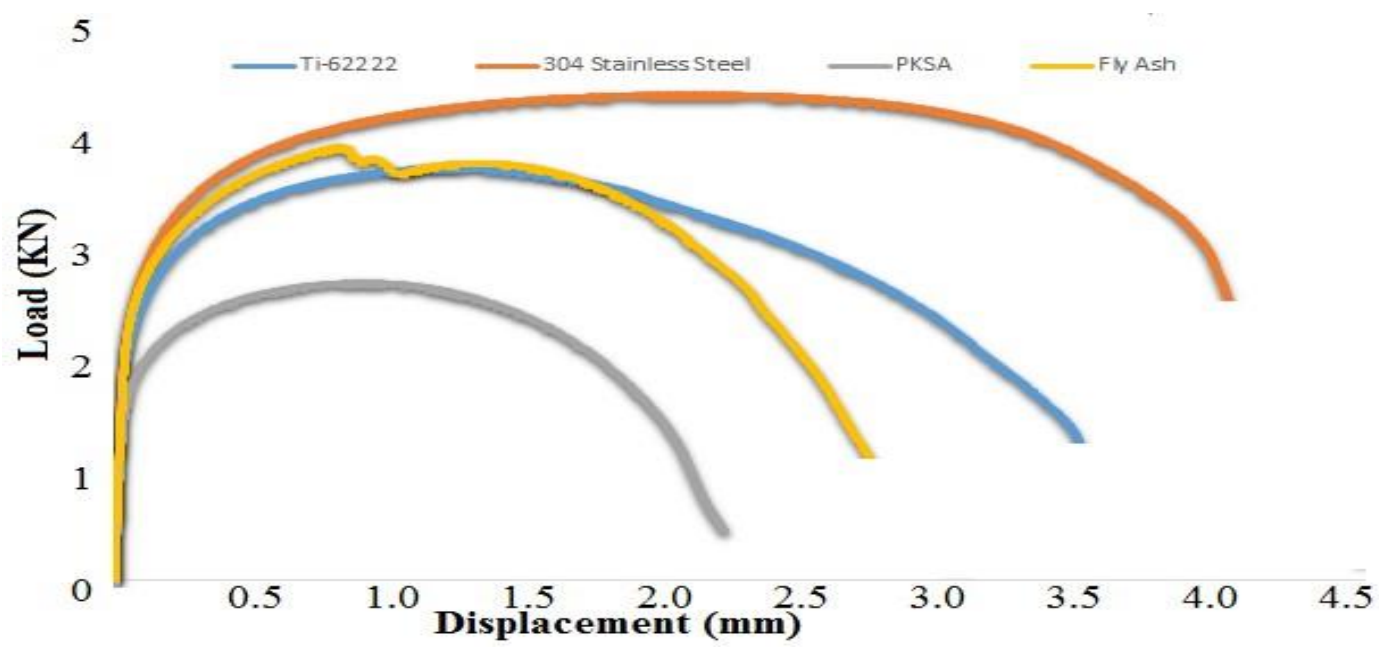

Figure 5: Load- Displacement curves for composite specimenss

\section{Conclusions}

1. Multi pass-FSP can be employed to produce 1100 aluminum sheet without macrodefects. After three cumulative passes, the grains of all reinforced samples are refined with an average grain size of $\sim 6.8 \mu \mathrm{m}$ in the stir zones, the 304 stainless steel reinforced sample has the best grain size of $5.1 \mu \mathrm{m}$

2. From this study, it can be concluded that reinforcement is an efficient method to enhance the mechanical properties of 1100 Aluminum alloys. With the combination of the new metal matrix composites fabricated in this study, higher mechanical properties of $1100 \mathrm{Al}$ are reached

\section{References}

Abegunde, O. O., E. T. Akinlabi, and D. Madyira. 2017. "Microstructural Evolution and Mechanical Characterizations of AL-TiC Matrix Composites Produced via Friction Stir Welding." Materiali in tehnologije 51(2): 297-306. http://mit.imt.si/Revija/izvodi/mit172/olayinka.pdf.

Adetunla, Adedotun, and Esther Akinlabi. 2018a. "Influence of Reinforcements in Friction Stir Processed Magnesium Alloys: Insight in Medical Applications." Materials Research Express. http://iopscience.iop.org/10.1088/2053-1591/aaeea8.

—. 2018b. "Mechanical Characterization of Al/Ti-6Al-4V Surface Composite Fabricated via

FSP: A Comparison of Tool Geometry and Number of Passes." Materials Research Express

5(11): $115015 . \quad$ http://stacks.iop.org/2053-

1591/5/i=11/a=115015?key=crossref.39787a6e1794fceb6ce7b9f453808ece. 
Ahmadkhaniha, D., M. Heydarzadeh Sohi, A. Salehi, and R. Tahavvori. 2016. "Formations of AZ91/A12O3 Nano-Composite Layer by Friction Stir Processing." Journal of Magnesium and Alloys 4(4): 314-18. http://dx.doi.org/10.1016/j.jma.2016.11.002.

Asif, M, K Chandra, and P S Misra. 2011. "Development of Aluminium Based Hybrid Metal Matrix Composites for Heavy Duty Applications." Journal of Minerals \& Materials Characterization \& Engineering, 10(14): 1337-44.

Charit, Indrajit, and Rajiv S. Mishra. 2017. "Effect of Friction Stir Processed Microstructure on Tensile Properties of an Al-Zn-Mg-Sc Alloy upon Subsequent Aging Heat Treatment." Journal of Materials Science and Technology 34(1): 214-18. http://dx.doi.org/10.1016/j.jmst.2017.10.021.

Hashemi, R., and G. Hussain. 2015. "Wear Performance of Al/TiN Dispersion Strengthened Surface Composite Produced through Friction Stir Process: A Comparison of Tool Geometries and Number of Passes." Wear.

Ikumapayi, O.M., E.T. Akinlabi, and J.D. Majumdar. 2018. "Review on Thermal, Thermomechanical and Thermal Stress Distribution during Friction Stir Welding." International Journal of Mechanical Engineering and Technology 9(8): 534-48.

Khayyamin, D, A Mostafapour, and R Keshmiri. 2013. "Materials Science \& Engineering A The Effect of Process Parameters on Microstructural Characteristics of AZ91 / SiO 2 Composite Fabricated by FSP." Materials Science \& Engineering A 559: 217-21. http://dx.doi.org/10.1016/j.msea.2012.08.084.

Khodabakhshi, F., A. Simchi, A. H. Kokabi, and A. P. Gerlich. 2015. "Friction Stir Processing of an Aluminum-Magnesium Alloy with Pre-Placing Elemental Titanium Powder: In-Situ Formation of an $\mathrm{Al}<\mathrm{inf}>3</ \mathrm{Inf}>\mathrm{Ti}$-Reinforced Nanocomposite and Materials Characterization." Materials Characterization 108: 102-14. http://dx.doi.org/10.1016/j.matchar.2015.08.016.

Luo, X.C. et al. 2018. "Tensile Properties of AZ61 Magnesium Alloy Produced by Multi-Pass Friction Stir Processing: Effect of Sample Orientation." Materials Science and Engineering: A 725(January): 398-405. http://linkinghub.elsevier.com/retrieve/pii/S0921509318305148.

Mishra, M. K. et al. 2018. "On the Microstructure Evolution in Friction Stir Processed 2507 Super Duplex Stainless Steel and Its Effect on Tensile Behaviour at Ambient and Elevated Temperatures." Materials Science and Engineering A 719(January): 82-92. https://doi.org/10.1016/j.msea.2018.02.032.

Mishra, R. S., Z. Y. Ma, and I. Charit. 2003. "Friction Stir Processing: A Novel Technique for Fabrication of Surface Composite." Materials Science and Engineering A 341(1-2): 307-10. Panwar, Narender, and Amit Chauhan. 2018. "Fabrication Methods of Particulate Reinforced Aluminium Metal Matrix Composite-A Review." Materials Today: Proceedings 5(2): 5933- 39. https://doi.org/10.1016/j.matpr.2017.12.194.

Rana, H.G., V.J. Badheka, and A. Kumar. 2016. "Fabrication of Al7075 / B4C Surface Composite by Novel Friction Stir Processing (FSP) and Investigation on Wear Properties." Procedia Technology 23: 519-28. http://linkinghub.elsevier.com/retrieve/pii/S2212017316300597.

Sivakumar, Vignesh Bose, D Raguraman, and D Muruganandam. 2014. "Review Paper on Friction Stir Welding of Various Aluminium Alloys." Journal of Mechanical and Civil Engineering:

46-52. 
Sunil, B. Ratna, G. Pradeep Kumar Reddy, Hemendra Patle, and Ravikumar Dumpala. 2016. "Magnesium Based Surface Metal Matrix Composites by Friction Stir Processing." Journal of Magnesium and Alloys 4(1): 52-61. http://dx.doi.org/10.1016/j.jma.2016.02.001.

Wu, Hongyan et al. 2015. "Nano-Mechanical Characterization of Plasma Surface Tungstenized Layer by Depth-Sensing Nano-Indentation Measurement." Applied Surface Science 324: 16067. http://dx.doi.org/10.1016/j.apsusc.2014.10.085.

Zhang, Chao et al. 2018. "Effect of Microstructures to Tensile and Impact Properties of Stir Zone on 9\%Cr Reduced Activation Ferritic/Martensitic Steel Friction Stir Welds." Materials

Science and Engineering: A 27(8): 558-63.

http://dx.doi.org/10.1016/j.tcm.2017.06.005\%0Ahttp://linkinghub.elsevier.com/retrieve/pii/S1 050173817300890\%0Ahttp://linkinghub.elsevier.com/retrieve/pii/S0921509318306920. 